\title{
Combining an Autologous Peripheral Nervous System "Bridge" and Matrix Modification by Chondroitinase Allows Robust, Functional Regeneration beyond a Hemisection Lesion of the Adult Rat Spinal Cord
}

\author{
John D. Houle, ${ }^{1}$ Veronica J. Tom, ${ }^{1}$ Debra Mayes, ${ }^{2}$ Gail Wagoner, ${ }^{2}$ Napoleon Phillips, ${ }^{2}$ and Jerry Silver ${ }^{3}$ \\ ${ }^{1}$ Department of Neurobiology and Anatomy, Drexel University College of Medicine, Philadelphia, Pennsylvania 19129, ${ }^{2}$ Department of Neurobiology and \\ Developmental Sciences, University of Arkansas for Medical Sciences, Little Rock, Arkansas 72205, and ${ }^{3}$ Department of Neurosciences, Case Western \\ Reserve University, School of Medicine, Cleveland, Ohio 44106
}

\begin{abstract}
Chondroitinase-ABC (ChABC) was applied to a cervical level 5 (C5) dorsal quadrant aspiration cavity of the adult rat spinal cord to degrade the local accumulation of inhibitory chondroitin sulfate proteoglycans. The intent was to enhance the extension of regenerated axons from the distal end of a peripheral nerve $(\mathrm{PN})$ graft back into the $\mathrm{C} 5$ spinal cord, having bypassed a hemisection lesion at $\mathrm{C} 3$. ChABC-treated rats showed (1) gradual improvement in the range of forelimb swing during locomotion, with some animals progressing to the point of raising their forelimb above the nose, (2) an enhanced ability to use the forelimb in a cylinder test, and (3) improvements in balance and weight bearing on a horizontal rope. Transection of the PN graft, which cuts through regenerated axons, greatly diminished these functional improvements. Axonal regrowth from the PN graft correlated well with the behavioral assessments. Thus, many more axons extended for much longer distances into the cord after ChABC treatment and bridge insertion compared with the control groups, in which axons regenerated into the PN graft but growth back into the spinal cord was extremely limited. These results demonstrate, for the first time, that modulation of extracellular matrix components after spinal cord injury promotes significant axonal regeneration beyond the distal end of a PN bridge back into the spinal cord and that regenerating axons can mediate the return of useful function of the affected limb.
\end{abstract}

Key words: spinal cord injury; regeneration; chondroitinase; neurotransplantation; extracellular matrix; plasticity

\section{Introduction}

After spinal cord injury (SCI), several different families of inhibitory extracellular matrix (ECM) molecules combine with reactive astroglia at the lesion site to form a dense scar that acts as a barrier to regenerating axons (Reier and Houle, 1988; Silver and Miller, 2004). Members of the chondroitin sulfate proteoglycan (CSPG) family are among the most potent groups of repulsive scar-associated ECM molecules (Snow et al., 1990; McKeon et al., 1991; Plant et al., 2001; Jones et al., 2003). Depending on the type, concentration, and geometric relationship to growth-promoting molecules in their territory, chondroitin-bearing proteoglycans can cause adult growth cones to turn abruptly, fasciculate tightly, or become dystrophic (Silver and Miller, 2004; Tom et al., 2004).

\footnotetext{
Received March 17, 2006; revised May 1, 2006; accepted June 2, 2006.

This research was supported by National Institute of Neurological Disorders and Stroke Grants NS26380 and NS25713, the Daniel Heumann Fund for Spinal Cord Research, and the Brumagin Memorial Fund. We thank Dr. Jed Shumsky for valuable input in the assessment of behavioral activity of SCl animals and Louise Bertrand for assistance with confocal microscopy. Drs. Marion Murray and Alan Tessler provided helpful comments and discussion of this work.

Correspondence should be addressed to John D. Houle, Department of Neurobiology and Anatomy, Drexel University College of Medicine, 2900 Queen Lane, Philadelphia, PA 19129. E-mail: jhoule@drexelmed.edu.

D0I:10.1523/JNEUROSCI.1166-06.2006

Copyright $\odot 2006$ Society for Neuroscience $\quad$ 0270-6474/06/267405-11\$15.00/0
}

Proteoglycans consist of a core protein decorated with long-chain glycosaminoglycan (GAG) side branches (Dow and Wang, 1998). Controlled administration of chondroitinase ABC (ChABC), an enzyme used by certain types of highly invasive bacteria to cleave the inhibitory side chains, has been used in mammals to degrade GAGs at spinal cord lesion sites, resulting in enhanced axonal regrowth and restoration of some downstream postsynaptic activity (Bradbury et al., 2002; Chau et al., 2004; Caggiano et al., 2005). However, whether regenerating axons contribute to the return of function has remained a matter of speculation.

Intraspinal transplants of fetal spinal cord tissue (Reier et al., 1992; Bregman, 1994), Schwann cells (Xu et al., 1995; Bunge, 2001), olfactory ensheathing glia (Li et al., 1998; Ramón-Cueto et al., 1998), genetically modified cells (Grill et al., 1997; Liu et al., 1999; Jin et al. 2002; Mitsui et al., 2005), and segments of peripheral nerve (PN) (David and Aguayo, 1981), the most classic approach, all provide an environment highly conducive to axonal regeneration. Axons readily penetrate each of these grafts, but their growth becomes severely restricted once they reencounter the CNS environment. In this study, we developed a PN graft model to bypass a hemisection lesion of the cervical spinal cord and direct regrowing axons to intermediate gray matter well distal to the level of injury. Advantages of this approach are that 
regenerating axons can be directed toward a functionally relevant target region and specific sources of regenerating axons can be traced as they approach (and hopefully cross) the PN graft-spinal cord interface (Aguayo et al., 1981; Friedman and Aguayo, 1985). The ability to test directly the contribution of regenerated axons to the return of function is particularly advantageous because the nerve bridge can be severed without causing additional damage to the cord. In the present study, we provide evidence that robust axonal regeneration beyond an SCI is facilitated by a PN guide in combination with treatment of the future distal graft insertion site with $\mathrm{ChABC}$. Improvements in motor activity are dependent on the presence of the PN graft and the formation of synaptic connections between regenerated axons and spinal cord neurons. However, some lingering behavioral improvement after bridge resection in some animals suggests that other plastic phenomena occurring locally may also play a role.

\section{Materials and Methods}

Spinal cord injury, ChABC treatment, and peripheral nerve grafts Adult (225-250 g) female Sprague Dawley rats were anesthetized with a ketamine $(60 \mathrm{mg} / \mathrm{kg})$ and xylazine $(10 \mathrm{mg} / \mathrm{kg})$ mixture. A cervical level 3 (C3) complete unilateral hemisection $(\mathrm{Hx})$ lesion cavity was created by aspiration in all animals. All procedures were performed in accordance with protocols approved by the University of Arkansas for Medical Sciences and Drexel University College of Medicine Institutional Animal Care and Use Committees and followed National Institutes of Health guidelines for the care and use of laboratory animals.

Group 1: modulation of spinal cord lesion site by enzymatic digestion. One end of an autologous, 1-week-long pre-degenerated tibial nerve was apposed to the rostral wall of the cavity, leaving the distal end free and unapposed to nerve or muscle tissue (supplemental Table $1 A$, available at www.jneurosci.org as supplemental material). Two weeks later, the C5 spinal cord was exposed and an $\sim 1 \mathrm{~mm}^{3}$ dorsal quadrant (DQ) lesion, extending to the approximate depth of the central canal, was created by aspiration. During hemostasis, the dura mater was sutured closed except for a small slit in which an infusion cannula (Alzet Brain Infusion kit; Durect, Cupertino, CA) was inserted. The hub surrounding the cannula (supplemental Fig. 1, available at www.jneurosci.org as supplemental material) was fixed to the dorsal surface of $\mathrm{C} 4$ and $\mathrm{C} 6$ vertebral bodies with a cyanoacrylate. The cannula was attached by a catheter tube to an osmotic minipump (Alzet model 1007D; Durect) that was filled with saline (as a control; $n=5)$ or ChABC ( $1 \mathrm{U} / \mathrm{ml} ; n=5$; Seikagaku America, Falmouth, MA) and primed earlier for immediate and continuous delivery of minipump contents at a flow rate of $0.5 \mu \mathrm{l} / \mathrm{h}$. Five microliters of ChABC was delivered into the DQ lesion before attaching the catheter to the cannula, and the minipump was secured between the shoulder blades. Five days later, animals were given an overdose of Euthasol (390 $\mathrm{mg} / \mathrm{kg}$ pentobarbital and $50 \mathrm{mg} / \mathrm{kg}$ phenytoin, i.p.) and perfused transcardially with $4 \%$ paraformaldehyde in $0.1 \mathrm{M}$ Sorenson's phosphate buffer. The C5 spinal cord surrounding the DQ lesion was removed, postfixed at $4^{\circ} \mathrm{C}$ for $4 \mathrm{~h}$, and then submersed in $20 \%$ sucrose for $24 \mathrm{~h}$ at $4^{\circ} \mathrm{C}$. Cryostat sections at $25 \mu \mathrm{m}$ in a transverse plane were prepared for immunocytochemical detection of chondroitin sulfate proteoglycan, the stub protein of digested CSPG, astroglial cells, and collagen type IV.

Group 2: identification of neurons regenerating their axon into a $P N$ graft. Two rats received a $\mathrm{C} 3 \mathrm{Hx}$ lesion and apposition of one end of a PN graft to the rostral cavity wall. The distal PN graft end was left unapposed to nervous tissue until 4 weeks later when the distal end of the graft was exposed, trimmed by $1 \mathrm{~mm}$, and exposed to Gelfoam saturated with True Blue (TB) (2\% solution; Sigma, St. Louis, MO). Animals were killed $7 \mathrm{~d}$ later, and tissue was preserved as described above. The entire brainstem and spinal cord rostral to the $\mathrm{C} 3 \mathrm{Hx}$ lesion (for propriospinal neurons) was sectioned in a coronal plane at a thickness of $50 \mu \mathrm{m}$. Sections were mounted serially on glass slides, dried, and coverslipped with Fluoromount (Biomedical Specialties, Santa Monica, CA). Each section was examined by fluorescence microscopy to detect the number and location of TB-labeled brainstem neurons that had grown an axon into the PN graft. The number of TB-labeled neurons in a specific region in each section was counted, and the total per specific region was tallied. The mean number per region was calculated for the two animals in this group.

Group 3: structural and functional recovery attributable to regenerating axons. A total of 18 rats ( $n=8$ saline treated; $n=10$ ChABC treated) were prepared as in group 1 above except that, after removal of the infusion cannula, the distal end of the PN graft was trimmed by $1 \mathrm{~mm}$ and apposed to the ventral floor of the C5 DQ cavity (see Fig. $2 A$ ) (supplemental Table $1 B$, available at www.jneurosci.org as supplemental material). Efforts were made not to expand the size of the lesion cavity, although obvious tissue debris associated with the cannula was removed by gentle aspiration from each cavity. This distal graft end was secured by suturing perineurium to dura mater and covered with supraspinal musculature. Animals were allowed to survive for 7 weeks, during which their behavioral activity was assessed weekly (see below). At 6 weeks after the C5 DQ lesion, animals were anesthetized and placed in a David Kopf Instruments (Tujunga, CA) stereotaxic head-holder device. Burr holes were made in the dorsal cranium, and biotinylated dextran amine (BDA) $(0.5$ $\mu \mathrm{l}$ of a $10 \%$ BDA solution; Invitrogen, Carlsbad, CA) was microinjected into the red nucleus contralateral to the spinal cord lesion and into the medullary reticular formation ipsilateral to the lesion (for coordinates, see Houle and Jin, 2001). One week later (7 weeks after the C5 DQ lesion/PN graft apposition and just after the final session of behavioral testing), the PN graft was exposed and ligated and cut at its midpoint. Behavioral activity was tested $24 \mathrm{~h}$ after this nerve cut, and the animals were then killed by an overdose of Euthasol followed by transcardial perfusion with paraformaldehyde. Transverse sections $(25 \mu \mathrm{m})$ were prepared through the $\mathrm{C} 2, \mathrm{C} 4$, and $\mathrm{C} 5$ spinal cord that contained the distal end of the PN graft. In separate wells, free-floating sections from each spinal cord level were processed for the presence of BDA-labeled axons by incubation in avidin-peroxidase (Invitrogen) followed by a diaminobenzidine reaction. Sections were mounted on glass slides and counterstained with thionin before being coverslipped with Permount (Fisher Scientific, Houston, TX). Transverse sections through the C2 spinal cord were examined to determine whether reticulospinal and rubrospinal pathways had been labeled with BDA. Sections through the C4 spinal cord were examined to confirm that descending pathways had been interrupted by the $\mathrm{C} 3 \mathrm{Hx}$ lesion. The presence of BDA-labeled axons at the C4 level ipsilateral to the lesion would indicate that some axons had been spared and were likely to be intermixed with regenerated axons in the C5 gray matter. Because regenerated axons could not be distinguished from spared axons in these animals, they were excluded from additional analysis if there was BDA labeling in the C4 spinal cord. Only those rats with anatomical verification of good graft apposition to the C3 and C5 injury sites, abundant labeling of both rubrospinal and reticulospinal tracts at the $\mathrm{C} 2$ level, no BDA-labeled axons at the $\mathrm{C} 4$ level ipsilateral to the $\mathrm{C} 3$ $\mathrm{Hx}$, and significant behavioral deficit at 1 week after injury were included in the report of behavioral activity. A total of 12 rats met these criteria ( $n=5$ for saline-treated control animals; $n=7$ for the ChABC-treated animals).

After this group had been analyzed, an additional four animals were prepared with chondroitinase treatment of the C5 DQ site before apposition of the distal end of the PN graft. Six weeks later, the PN graft was exposed and cut through its midpoint. The distal cut end was immersed in BDA for $1 \mathrm{~h}$ to label all axons within the graft by a diffusion fill technique. This approach eliminated the possibility of including in our analysis BDA-labeled axons arising from contralateral pathways (such as the reticulospinal tract) that had not grown through the PN graft but that had sprouted into the gray matter ventral to the C5 DQ lesion. This labeling approach gave a more comprehensive estimate of the course within the spinal cord and the number of axons that had regenerated into and out of the PN graft, although their source could not be determined. Animals were killed $2 \mathrm{~d}$ later, and tissue sections were processed as described above.

Group 4: control for effects of ChABC treatment alone. To test for changes in behavioral outcome that might be attributed to treatment with $\mathrm{ChABC}$, four animals were prepared with a C3 Hx lesion, PN graft, and C5 DQ lesion treated with ChABC as described previously. After 
removal of the infusion cannula, the distal end of the PN graft was left unapposed and covered with supraspinal muscles. Behavioral activity was tested over a 7 week period.

\section{Axonal tracing}

To quantify maximal length traversed by axons growing back into the spinal cord, digital images from at least five representative transverse sections through the C5 PN graft-spinal cord interface were captured, and montages were created from each $\mathrm{ChABC}$ - or saline-treated animal. In each montage, the distance of the tip of the farthest extending axon from the distal end of the PN graft was measured as a straight line using MetaMorph imaging software (Universal Imaging Corporation, Downingtown, PA). Only axons that could be traced ventrally from the area of the PN graft and that had an expanded terminal end were included in this analysis. The mean length of the longest axon from each animal was calculated and tested for significant difference using Student's $t$ test.

\section{Immunocytochemistry}

For animals of group 1, the unfixed cervical spinal cord was removed and blocked to include $2 \mathrm{~mm}$ of tissue rostral and $2 \mathrm{~mm}$ of tissue caudal to the C5 injury site. Blocks were fresh frozen on dry ice, and $25 \mu \mathrm{m}$ cryostat sections were mounted in serial order on an alternating set of Superfrost/ Plus (Fisher Scientific) slides. This ensured that each slide contained tissue sections through the rostral, middle, and caudal portions of the lesion site, with adjacent sections on successive slides. There were four sections on each slide $\sim 600 \mu \mathrm{m}$ apart from one another (yield was $\sim 20$ slides from each block). Slides were stored at $-80^{\circ} \mathrm{C}$ until immunocytochemistry (ICC) was performed. Sections were incubated in phosphatebuffered $4 \%$ paraformaldehyde for $15 \mathrm{~min}$. They were then washed with $0.1 \mathrm{M}$ Sorenson's phosphate buffer before being permeabilized in Triton X-100 PBS (T-PBS) for $15 \mathrm{~min}$ and blocked for nonspecific reactivity with normal goat serum/T-PBS, 1:20 for 15 min. Primary antibodies were applied to the sections and incubated overnight at room temperature. The primary antibodies were against the following: collagen type IV (1:1000; Chemicon, Temecula, CA), chondroitin sulfate proteoglycan (1:250, clone CS-56; Sigma), stub protein after ChABC digestion (1:100, clone 2-B-6; Seikagaku America), and glial fibrillary acidic protein (GFAP) for astrocytes (1:500; DakoCytomation, Carpinteria, CA). Sections were washed, incubated with either fluorescein-conjugated or rhodamine-conjugated secondary antibody for $90 \mathrm{~min}$, and coverslipped with Fluoromount mounting medium (Biomedical Specialties). All sections were examined under fluorescent light with a Zeiss (Thornwood, NY) Axioskop microscope.

For animals of group 3, some of the free-floating sections through the C5 PN graft-spinal cord interface were reacted with ExtrAvidin-cyanine 3 (Sigma) to detect BDA-labeled axons and then incubated with primary antibody to the low-affinity nerve growth factor receptor (1:200, 192 clone for p75; Chemicon) to detect Schwann cells in association with regenerated axons. In another set of sections, the formation of synaptic contacts by BDA-labeled axons with spinal cord neurons was detected by reaction with primary antibody to synaptophysin (1:200; Sigma). FITCtagged rabbit anti-mouse IgG (Sigma) was used as the secondary antibody in both situations. Sections were examined with a Leitz (Wetzlar, Germany) confocal microscope.

\section{Image analysis}

From sections prepared for ICC detection of ECM and non-neuronal cell components in the injured spinal cord, the proportional area of the lesioned spinal cord occupied by immunoreactive profiles was obtained from digitized images using a CoolSnap FX CCD camera (Roper Scientific, Tucson, AZ) and MetaMorph image analysis software. All prepared sections were examined within $7 \mathrm{~d}$ of the immunocytochemical reaction using the same light intensity, and all images were captured at a constant exposure time. For each image, contrast settings were adjusted (i.e., thresh holding) for a given antibody in a simultaneously processed group until the software could accurately outline the immunoreactivity within the prospective structures. A computer-drawn box outlining an area $\sim 940 \times 270 \mu \mathrm{m}$ was superimposed on tissue sections just ventral to the lesion border (supplemental Fig. 2, available at www.jneurosci.org as supplemental material), and densitometric measures of the immunore- active content were made. A second region just ventral to the first region was highlighted and subjected to densitometry, and the same followed for a third more ventral area of analysis. A univariate ANOVA was performed to detect statistical differences $(p<0.05)$ between a single treatment approach and the saline-treated control group, and post hoc use of the Newman-Keuls test determined significant differences between the experimental and control groups.

\section{Behavioral testing}

Animals were habituated to the testing condition preoperatively. Animals in groups 3 and 4 were assessed for baseline behavioral activity 1 week before the $\mathrm{C} 3 \mathrm{Hx}$ injury and then weekly beginning 1 week after apposition of the distal end of the PN graft. All sessions were videotaped for later analysis by individuals blinded to the treatment of the animal. Vertical exploration (cylinder test), rope walk, and forelimb swing during open-field locomotion were adapted from Kim et al. (2001) and Shumsky et al. (2003). Student's $t$ test was used to determine statistical significance between ChABC-treated and saline-treated groups at individual weekly intervals.

Cylinder test. Animals were placed in a Plexiglas cylinder $(17.8 \mathrm{~cm}$ in diameter and $35.5 \mathrm{~cm}$ in height) for $4 \mathrm{~min}$. During spontaneous rearing and vertical exploration, the number of forepaw contacts (left, right, and both) with the cylinder wall was recorded and expressed as a percentage of total placements. No bias in forepaw use was demonstrated before spinal cord injury.

Rope test. Before injury, rats were trained to walk across a $100-\mathrm{cm}$ long, 5-cm-wide suspended rope. The number of slips with either forepaw or falls from the rope was counted over five consecutive trials and expressed as the percentage of errors over the total number of steps. Animals that could not cross the rope were assigned 100\% error.

Forelimb swing. The angle (relative to the body trunk) of forelimb movement that was displayed consistently during open-field locomotion (supplemental movies 1-5, available at www.jneurosci.org as supplemental material) was rated with a score of 1 for movement $<90^{\circ}, 2$ for movement of $90^{\circ}, 3$ for movement $>90^{\circ}, 4$ for paw placement above the nose when stationary, or 5 for grooming motion above the level of the eyes. The pattern of affected forelimb use was graded in the first minute of activity, during which at least 10 steps were recorded.
Saline

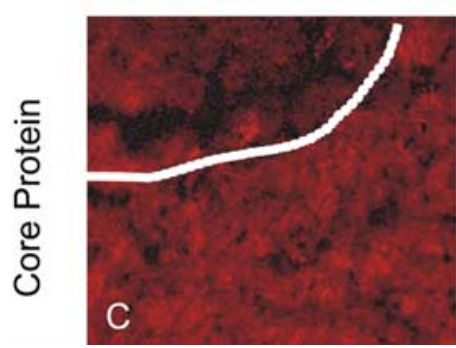

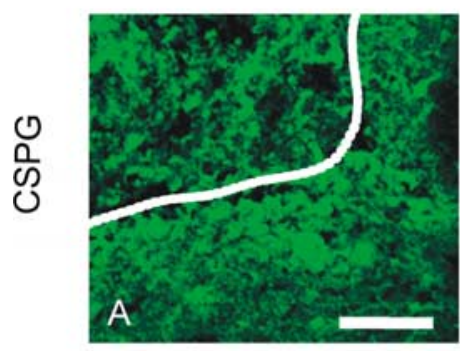

\section{Chondroitinase}
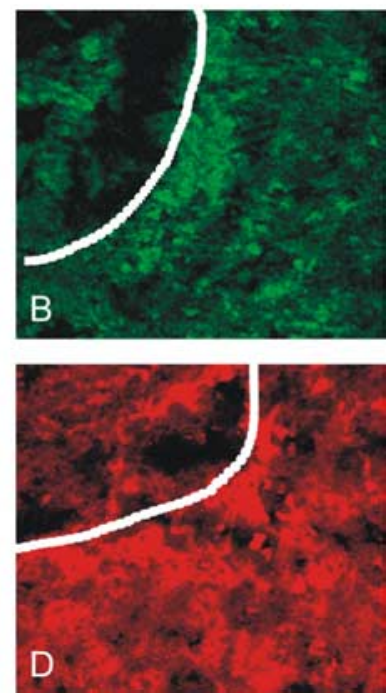

Figure 1. Immunocytochemical detection of CSPG and stub antigen/core protein adjacent to a dorsal quadrant lesion $5 \mathrm{~d}$ after treatment with saline (control) or ChABC. The lesion cavity is positioned at the top left, with intact tissue to the right and below the dotted line. After $\mathrm{ChABC}$ treatment $(\boldsymbol{B})$, CSPG-immunoreactivity is condensed right at the lesion relative to the more diffuse labeling observed adjacent to saline-treated lesions $(\boldsymbol{A})$. In contrast, immunoreactive staining for core protein greatly increased after $\mathrm{ChABC}$ treatment $(\boldsymbol{D})$ compared with the salinetreated lesion (C). Scale bar, $100 \mu \mathrm{m}$. 


\section{Results}

C5 DQ distal graft site: distribution of CSPGs in control animals and after ChABC treatment

In saline-treated animals (group 1), CSPG-IR was diffusely spread throughout the spinal cord ventral to the injury site, and the contralateral side of the cord contained very little immunoreactivity except in gray matter adjacent to the central canal. There was no apparent structural arrangement to the CSPG-IR close to the lesion site, although some of the immunostaining appeared to be closely associated with cells lying in the cavity wall (Fig. $1 A$ ). After treatment with chondroitinase, CS-56 immunostaining was nearly absent in the spinal cord ventral to the cavity lesion (Fig. $1 B$ ). ChABC-treated animals exhibited a twofold to threefold decrease $(p<0.01)$ in the densitometric measurement of CSPG-IR in all regions of the spinal cord ventral to the lesion, including the area comprising the cavity wall. Relative densitometric measures of CSPG, stub protein, GFAP, and collagen IV are provided in supplemental Figure 2 (available at www.jneurosci.org as supplemental material).

The spinal cord of saline-treated animals contained no stub antigen immunoreactivity close to the lesion cavity (Fig. $1 C$ ) or in more ventral areas of the spinal cord. Stub protein-IR of the digested GAGs was obvious after ChABC treatment, especially close to the cavity wall in which many large deposits of immunoreactive material were clustered (Fig. 1D). The density of stub protein-IR increased threefold to fourfold $(p<0.01)$ after treatment with $\mathrm{ChABC}$ in regions 1 and 2 of the spinal cord ventral to the lesion. There was no significant difference in immunoreactivity in region 3 , ventralmost from the lesion cavity.

Collagen IV immunostaining formed part of the thin connective tissue layer surrounding blood vessels but was also present diffusely within the extracellular matrix of the injured spinal cord (data not shown). There was no obvious difference in the distribution of collagen IV-IR between the injured and uninjured sides of the spinal cord, except immediately adjacent to the lesion cavity in which blood vessels were oriented along the cavity wall. This discontinuous layer of collagen IV-IR was especially evident in the saline-treated animals in contrast to ChABC-treated animals. Treatment with ChABC did not appear to disrupt the overall vascular composition in the gray matter ventral to the lesion, although the tendency toward orientation of vessels tangential to the cavity wall was not as pronounced as in saline-treated animals.

GFAP-IR defined the distribution of intensely reactive astrocytes throughout the gray matter ventral to the lesion site, with a
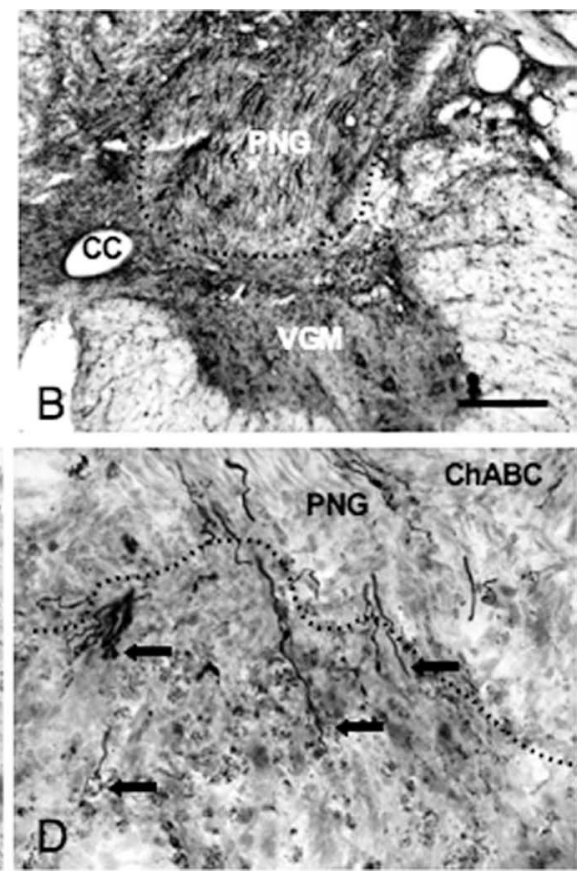

Figure 2. Evidence for axonal growth from a PN graft into the spinal cord. $\boldsymbol{A}$, This diagram depicts the positioning of the graft (D) axons are found in the graft (PNG) close to the interface (dotted line) with the spinal cord, with some crossing into the (VGM). CC, Central canal. Thionin counterstain. C, Most BDA-labeled axons (arrows) failed to cross the PI interface when the lesion was treated with saline. Several axons with a bend at the terminal end appear to be heads). $\boldsymbol{D}$, Treatment of the $C 5$ lesion with ChABC was sufficient to allow the extension of many axons (arrows) across the PN
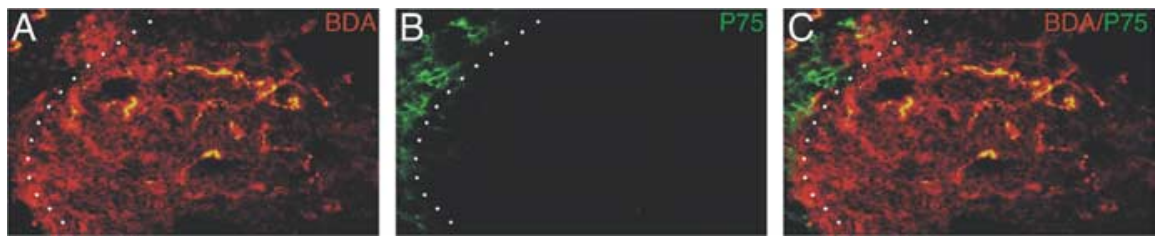

Figure 3. BDA-labeled axons have extended from a PN graft (top left out of frame) into spinal cord gray matter independent from Schwann cells labeled with an antibody to 75 receptor ( $g r e e n$ in $\boldsymbol{B}$ ). Overlap of the images $(\boldsymbol{C}$ ) indicates that most $\mathbf{S c h w a n n}$ cells remain within the PN graft, disengaged from the growth of regenerated axons into the spinal cord.

tendency toward increases in expression at the lesion border (data not shown). Quantitatively, there was no significant difference in the general patterning of GFAP within astroglia along the cavity wall for ChABC-treated animals compared with the salinetreated animals, but there was a trend toward a decrease in intensity of GFAP staining in the ChABC treatment group with increasing distance from the cavity floor.

\section{Axonal growth into PN grafts}

All neurons in the brainstem that were retrogradely labeled from the PNS graft with True Blue were considered to have grown axons into the PN graft. The mean \pm SEM number of neurons identified within animals of group 2 was $1456 \pm 3$ (supplemental Fig. 3, available at www.jneurosci.org as supplemental material). Most were located within the medullary and pontine reticular formation (55\%), and neurons from raphe nuclei (15\%), locus ceruleus (10\%), and the red nucleus (5\%) also made important contributions. Each PN graft also contained axons originating 


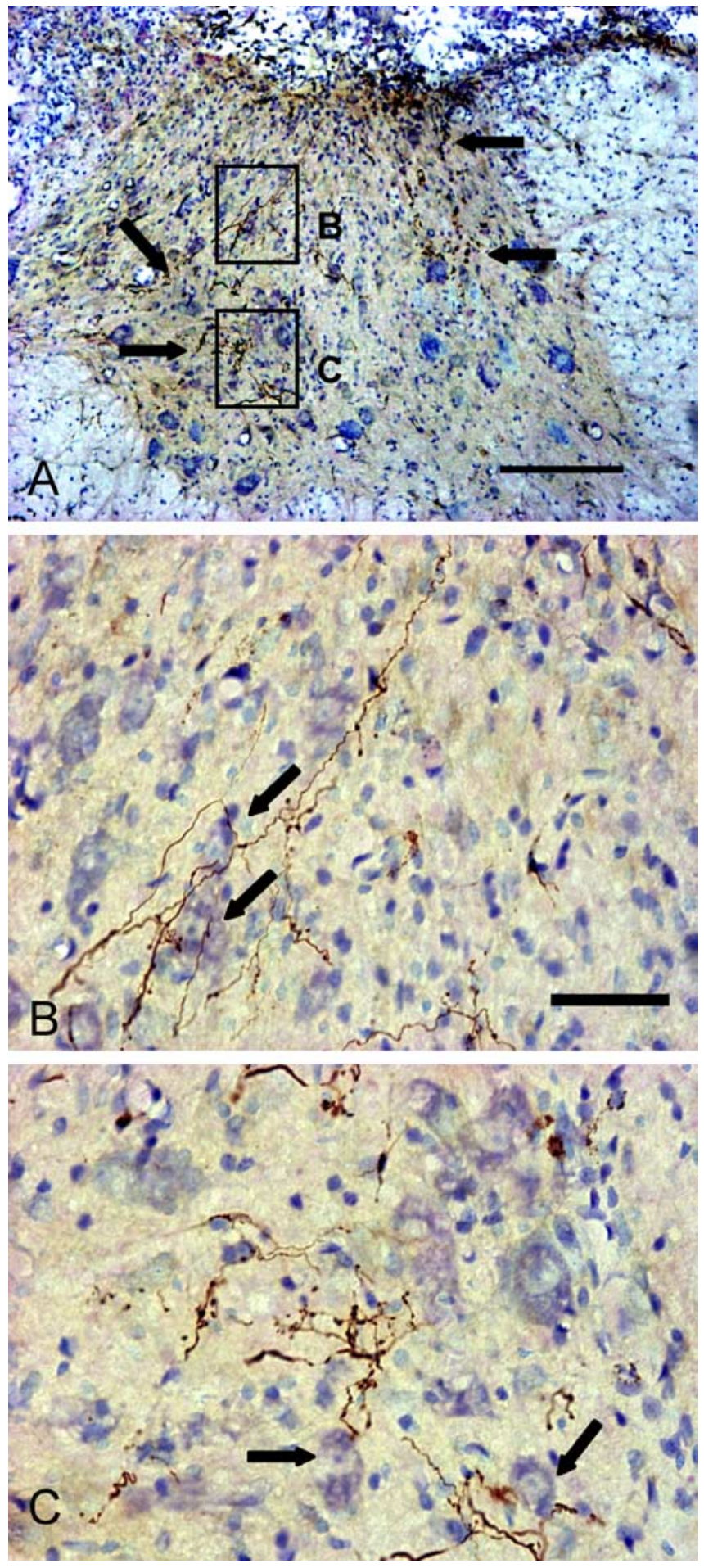

Figure 4. Relationship of BDA-labeled axons with spinal cord neurons. A, Spinal cord tissue ventral to the PN graft (top of image) contained many regenerated axons (arrows), with some extending toward a motoneuron pool in the medial ventral horn (bottom left). $B, C$, Highermagnification images from boxes outlined in $\boldsymbol{A}$ show branching of BDA-labeled axons and multiple varicosities along their length. Possible anatomical contact between regenerated axons and thionin-stained spinal cord neurons is evident (arrows). Scale bars: $A, 250 \mu \mathrm{m} ; \boldsymbol{B}, \boldsymbol{C}$, $50 \mu \mathrm{m}$.

from nearly 900 propriospinal neurons located in cervical segments rostral to the $\mathrm{C} 3 \mathrm{Hx}$ lesion. The extent of axonal regeneration into the PN grafts was comparable with previous studies of C3 Hx injury performed in the laboratory.

\section{Axonal growth into the spinal cord}

The distinction between the PN graft and spinal cord tissue was made according to the obvious orientation of Schwann cells and BDA-labeled axons uniformly down the dorsal-to-ventral course of the PN graft and the often abrupt ending of axons at the interface with spinal cord tissue (Fig. $2 B, C$ ) regardless of whether the lesion cavity had been treated with saline or ChABC. The absence of Schwann cell invasion into the spinal cord, as highlighted by immunocytochemical staining for p75, the low-affinity NGF receptor (Fig. 3), indicated that extension of Schwann cells into the spinal cord was not correlated with axonal outgrowth from the PN graft.

The best example of axonal outgrowth across an interface after saline treatment is shown in Figure 2C. A few short axons were found just across the PN graft-spinal cord interface, with a rare fiber extending $>20-30 \mu \mathrm{m}$ into the spinal cord. Most of these axons appeared to be of very fine caliber and exhibited little branching. Many axons stopped abruptly on the graft side of the interface or turned away from the spinal cord and appeared to grow back toward the $\mathrm{C} 3$ end (Fig. 2C). In contrast, axon outgrowth was far reaching in animals that had been treated with ChABC. Many axons traversed the interface (Fig. 2D), extended primarily in a dorsoventral direction within the intermediate gray matter, and often grew for distances $>1000 \mu \mathrm{m}$ (Fig. 4A). The mean length of the longest axon extending into the spinal cord after saline treatment was $11.5 \pm 5.3 \mu \mathrm{m}$ (from 15 samples), which was significantly less $(p<0.01)$ than that observed after treatment with ChABC (1271.6 $\pm 48.5 \mu \mathrm{m}$, from 112 samples). Few axons were found within white matter apposed to the PN graft, but some short axons could be seen in the ventral white matter (Fig. 4A). Most regenerating axons remained within the immediate segment of their entrance into the spinal cord, not venturing rostral or caudal into adjacent segments. Regenerated axons had few proximal varicosities, whereas their distal ends had multiple branches with prominent varicosities that often ended with an enlarged terminal (Figs. $4 B, C, 5 A$ ). Possible anatomical contact between regenerated axons and spinal cord neurons was frequently observed and was characterized by bouton-like axon endings approximating spinal cord neurons (Figs. $4 B, C, 5 B-D$ ). Indeed, many ventral motoneurons were surrounded by multiple branches of regenerated axons (Fig. 5C,D). Double-labeled sections demonstrated that many regenerated axons were colocalized with synaptophysin immunoreaction product on the surface of intermediate gray (Fig. 6C) and ventral motoneurons, suggestive of synaptic contacts distal to the injury site. Multiple sites of synaptophysin immunoreactivity occurred along the length of regenerated axons as well as on the expanded terminal endings (Fig. 6A-C).

Our evaluation protocol was designed to ensure that BDAlabeled axons ventral to the graft-host interface were regenerated fibers, but it remained possible that some BDA-labeled axons had sprouted from the contralateral spinal cord because the ReST has some bilateral projections that could cross into the spinal cord close to the $\mathrm{C} 5$ lesion site. Figure 7 demonstrates the results of a different technical approach to labeling axons within the PN graft. Diffusion fill from the cut midportion of the graft resulted in more extensive labeling of axons than was apparent after microinjection of BDA into the red nucleus and reticular formation (compare Figs. $7 C, 2 B$ ). A per section comparison also suggested that the diffusion fill method labeled more axons extending into the spinal cord. Based on examination of sections used to prepare Figure 7, it appears that $\sim 20-25 \%$ of the axons within the PN graft cross into the spinal cord. There was only sparse growth or 
extension of labeled axons beyond the segment in which they entered the spinal cord. BDA-labeled spinal cord neurons adjacent to the graft-cord interface also were found, indicative of host cells that had grown an axon into the PN graft, reaching at least to its midpoint.

\section{Behavioral assessment}

Damage to the right hindlimb caused by removal of the tibial nerve (which was used as an autologous graft) resulted in impaired function of all animals in our testing situations. Quantification of forelimb use during attempted vertical exploration showed no significant improvement in the placement of the right paw on the cylinder with ChABC treatment, which likely was attributable in part to the right hindlimb handicap, affecting stability during the rising phase of exploration. Difficulty with balance often resulted in animals falling sideways, especially as they attempted to rise up on their hindlimbs. Despite this difficulty, we detected qualitative differences in forelimb use in most ChABC-treated animals compared with the saline-treated group. Placing animals in the confines of a glass cylinder helped them assume a more upright posture and permitted observation of forelimb use during attempted standing on four limbs. Figure $8 \mathrm{~A}$ demonstrates apparent weight support by the affected forelimb in a ChABC-treated animal with obvious plantar placement of the forepaw. The ability to weight support and to plantar place was lost $1 \mathrm{~d}$ after severing of the PN graft (Fig. $8 B$ ). Saline-treated animals (Fig. $8 C$ ) were unable to use the affected forelimb for weight support, and the forepaw remained dorsiflexed (Fig. 8C).

The activity of animals on the rope walk also was impaired by hindlimb peripheral nerve damage. They had great difficulty maintaining their balance on the rope es-

pecially at early postgraft periods. However, after 3-4 weeks, three of seven of the ChABC-treated animals were able to rise up on both forelimbs (Fig. 8D) and attempted to walk along the rope, although they still had great difficulty completing a single pass. Plantar placing and forepaw gripping was a characteristic of the best ChABC-treated animals (three of seven), and the use of the injured forelimb in these movements was lost after severing the PN graft (Fig. $8 E$ ). None of the saline-treated animals showed any capacity to rise up to move along the rope or to exhibit weight support or plantar placing (Fig. $8 F$ ).

Forelimb swing in an open field (albeit with impaired hindlimb function) was assessed in terms of range of motion relative to the body trunk and head. At 1 week after C5 injury and distal graft apposition, there was no significant difference between ChABC- and saline-treated animals (Fig. 9) (supplemental Table 2 , available at www.jneurosci.org as supplemental material) because all animals had scores of 1 or 2 (forelimb swing less than or equal to $\left.90^{\circ}\right)$. At 3 weeks after treatment, ChABC-treated animals began to show improvement in range of motion that reached significance at 4 weeks compared with saline-treated animals. This difference was maintained through week 7 when ChABC-treated animals had a mean score of 2.86 (nearly full swing forward during locomotion) compared with 1.6 for saline-treated animals (two of five rats failed to reach $90^{\circ}$ during forelimb swing after 7 weeks) (for animal behavior at 1 and 7 weeks after distal graft apposition, see supplemental movies $1-5$, available at www.jneurosci.org as supplemental material). Nearly half of the ChABC-treated animals (three of seven) were capable of arm movements past $90^{\circ}$ to reach the nose or face (achieving a score of 4 during some point in the 7 week behavioral assay period), although none of the animals regained the capacity for full grooming or consistently exhibited a score of 4 or more. None of the saline-treated rats achieved a score above 2 at any stage of the testing. Importantly, five of seven ChABC-treated rats demonstrated a considerable degree of functional recovery with a rating of 3 or 4 at week 

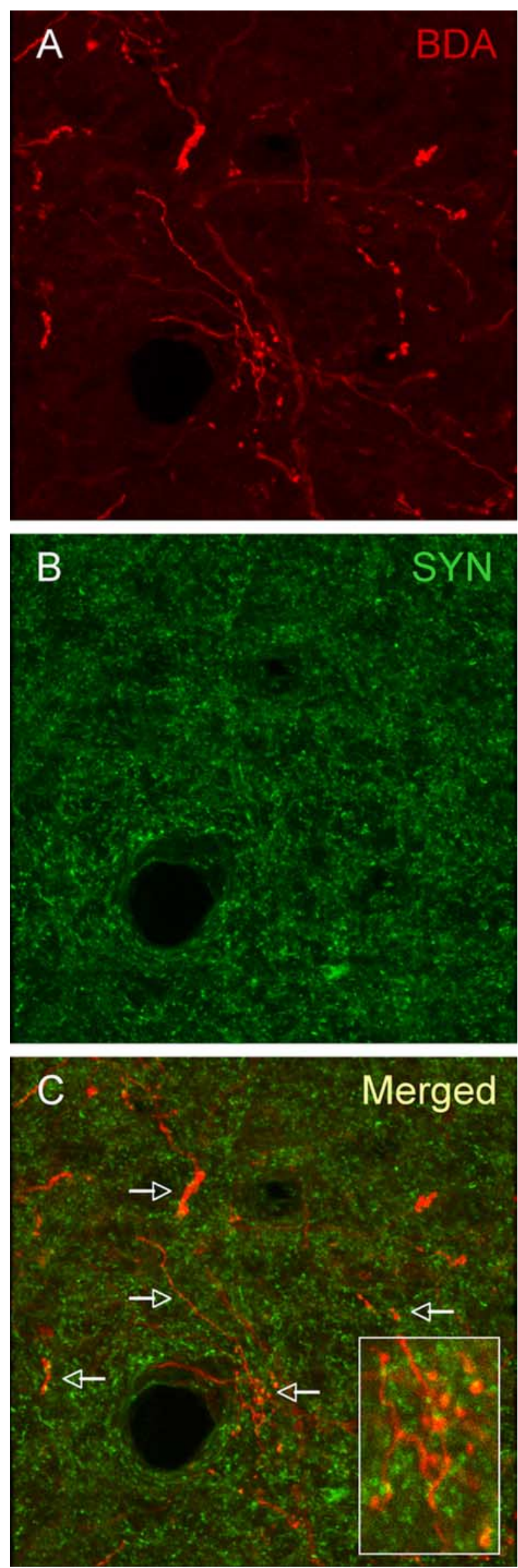

7. There was a decrease in range of motion of $1-2$ points $1 \mathrm{~d}$ after severing the PN graft in all seven ChABC-treated animals but no change in score of any of the saline-treated animals after the graft was cut (Fig. 9) (supplemental Table 2, available at www.jneurosci.org as supplemental material). However, in two ChABC-treated animals, recovered forelimb function did not disappear completely back down to baseline levels seen at 1 week. This suggests an additional source of information transfer into the spinal cord caudal to the $\mathrm{C} 3$ Hx lesion (see Discussion).

All tissue sections through the C5 site of apposition were examined in a blinded manner for the extent of axonal growth to test whether there was a correlation between axonal regeneration with behavioral recovery. A ranking of the overall extent of axonal outgrowth was performed based on a qualitative assessment of axon number and distribution through spinal cord gray matter, with animals exhibiting no axonal outgrowth receiving a 0 , a +1 for a small number of axons close to the interface, $a+2$ for axonal outgrowth extending into the intermediate gray, and $\mathrm{a}+3$ for animals with robust outgrowth reaching areas of the ventral horn. Each of the three ChABC-treated animals that achieved a rating of 4 in forelimb mobility exhibited substantial axonal outgrowth into the spinal cord (supplemental Table 2, available at www.jneurosci.org as supplemental material). Two other ChABC-treated rats that achieved scores of 3 were ranked as +2 , whereas the two remaining rats that did not score above a 2 had an axonal outgrowth rank of +1 . The five saline-treated animals were ranked as 0 or +1 . Thus, the rough estimation of total axonal outgrowth correlated well with behavioral activity, suggesting that greater axonal outgrowth should yield better recovery.

Behavioral analysis of animals in group 4 (ChABC-treated but unapposed distal end of PN graft) indicated no significant improvement in any task for which they were tested. Scoring of rotational arm motion was similar to that observed in salinetreated animals of group 3, indicating the absence of a significant effect of ChABC treatment alone on local axonal sprouting or other synaptic changes that might contribute to an improvement of forelimb use.

\section{Discussion}

The present study has tested whether ChABC modulation of the local proteoglycan-rich milieu surrounding a spinal cord cavitation site would create an environment more conducive to the extension of regenerated axons from the distal end of a PN graft back into the spinal cord. Robust axonal outgrowth after treatment with ChABC contrasted vividly with the scarcity of fibers crossing a saline-treated lesion site. Bouton-like structures on regenerating axons in close association with interneurons and motoneurons and overlap of BDA-labeling with synaptophysin-IR imply reconnection of descending spinal pathways with appropriate target neurons beyond the distal end of the graft. Behavioral analyses revealed significant improvement in forelimb function in the PN-bridged/ChABC-treated groups compared with the control animals. Transection of the PN graft

Figure 6. Indications of synaptic contact between regenerated axons and spinal cord neurons. $A$, The distribution of BDA-labeled axons is depicted in $A$, and the distribution of synaptophysin (SYN)-IR in the same field is presented in $\boldsymbol{B}$. Merging of these images $(\boldsymbol{C})$ provides an indication of the presence of synaptic contacts associated with regenerated axons (arrows). Multiple synaptic sites are found along the length of regenerated axons as well as on the cluster of fibers found in the bottom center of the image (highlighted in the inset). 
resulted in a loss of the behavioral gains, strongly suggesting that regenerated axons played a significant role in the restoration of function. These results demonstrate, for the first time in a model of adult SCI, the potential to promote extensive axonal regeneration and functional recovery when an autologous nerve graft is combined with modulation of inhibitory ECM.

The distal end of the PN graft, which had been apposed to a $\mathrm{C} 3 \mathrm{Hx}$ lesion 3 weeks earlier, was trimmed before apposition to the C5 site. This intervention cuts through regenerating axons and, thus, has the potential to elicit a conditioning lesion response in the previously damaged neurons (McQuarrie et al., 1977). Although the conditioning phenomenon can enhance the intrinsic growth capacity of the regenerating neurons, it does not promote significant axonal regrowth centrally in the classic PN bridging model (Richardson et al., 1980; and our present results) or in other types of CNS injury (Neumann et al., 2002; Filbin, 2003). Previous injury of peripheral sensory fibers in the sciatic nerve can induce the central processes of dorsal root ganglion (DRG) neurons to grow farther into the core of a dorsal column lesion but rarely beyond. Even maximal conditioning brought about by double lesions of the sciatic nerve before lesion of the dorsal column (Neumann et al., 2005) or by inducing an inflammatory response in DRG neurons before lesion of dorsal roots ( $\mathrm{Ri}$ chardson and Issa, 1984) yields minimal regeneration within the CNS compartment. Recently, it was reported that intense preconditioning of sensory axons via zymosan-induced inflammation in the DRG before root crush followed by ChABC administration into the dorsal root entry zone (DREZ) allowed robust regeneration into the spinal cord (Steinmetz et al., 2005). Importantly, ChABC application by itself was essentially ineffective in promoting recovery. Preconditioned regrowth of axons in a PNS environment appears to be an especially strong, regeneration-promoting stimulus when combined with inhibitory matrix modification. However, stimulating DRG neurons by inflammation after injury of the dorsal roots failed to cause any axons to regenerate through the DREZ, even in the presence of ChABC. Fortunately, although use of the PN bridge after cord injury has similar advantages of the DREZ model by allowing for lengthy preconditioning and regeneration of CNS axons in a PNS environment, it also is effective in the more clinically relevant postinjury situation of the present study.
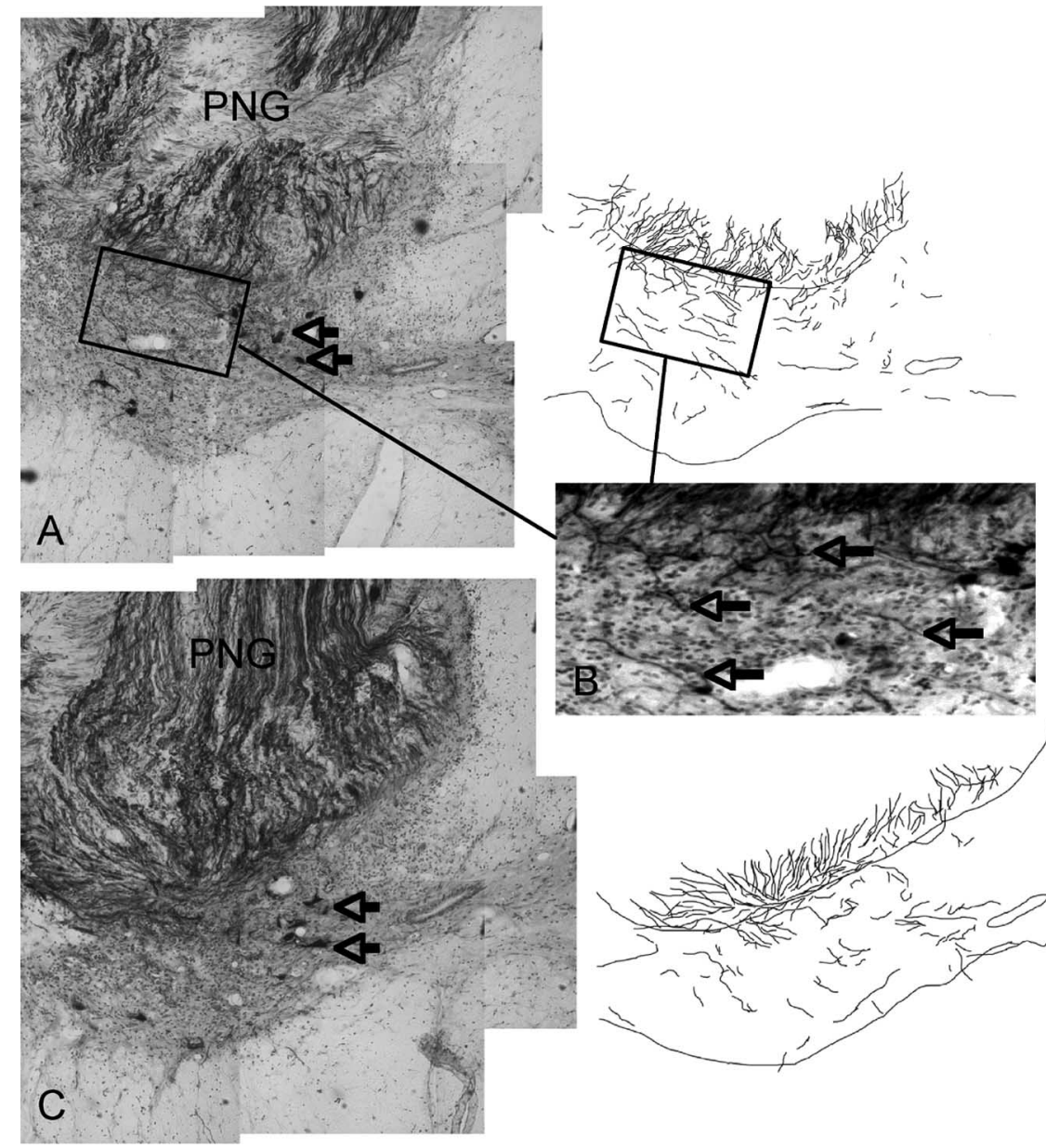

Figure 7. Reconstruction of axonal outgrowth from PN grafts exposed to BDA. The entire PN graft (PNG) appears filled with BDA-labeled axons after exposing the cut end of the middle of the graft to BDA. The distribution of regenerating axons within the spinal cord is presented in tracings next to their respective montage of images. Several retrogradely filled spinal cord neurons (arrows) close to the graft-host interface are indicative of neurons that grew an axon into the PN graft.
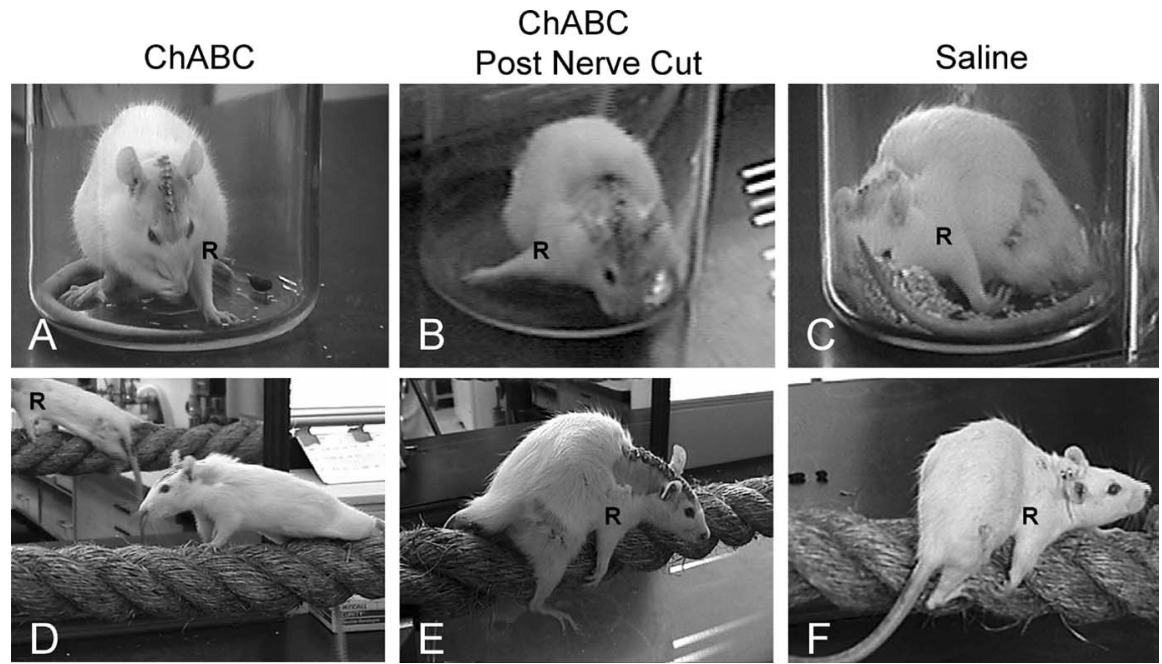

Figure 8. Examples of forelimb use at rest and during rope walking. Some of the images are from a mirror facing the camera on the far side of the testing platform. Some animals treated with $\operatorname{ChABC}(\boldsymbol{A}, \boldsymbol{D})$ before placement of the distal PN graft demonstrated the ability to use the affected forelimb for balance during grooming and movement along a suspended rope compared with the absence of such use in saline-treated animals $(\boldsymbol{C}, \boldsymbol{F})$. Forelimb use that was recovered after $\mathrm{ChABC}$ treatment $(\boldsymbol{A}, \boldsymbol{D})$ was absent for at least $24 \mathrm{~h}$ after severing the PN graft $(\boldsymbol{B}, \boldsymbol{E})$. R indicates the injury-affected right forelimb. 


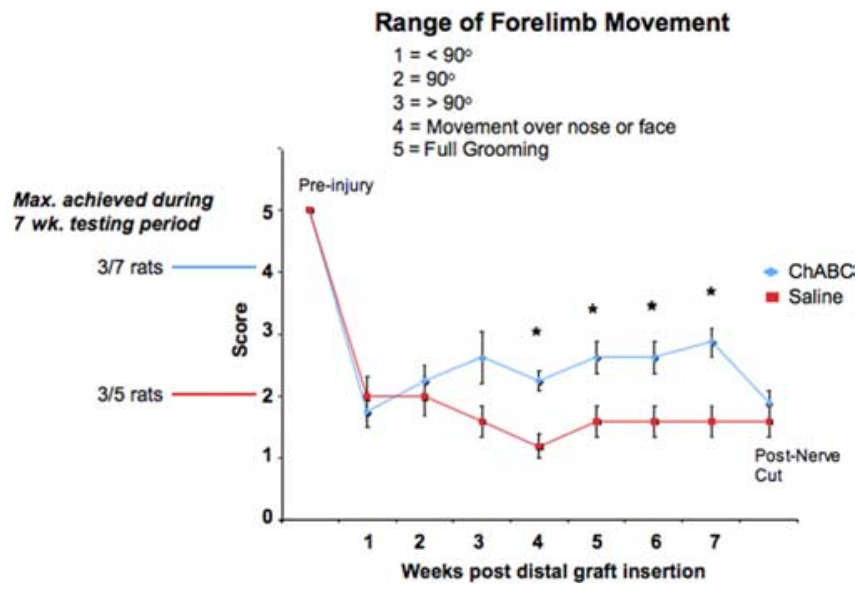

Figure 9. Animals in both groups exhibited a significant decrease in the range of motion immediately after creation of the $\mathrm{C} 5 \mathrm{DQ}$ lesion (compare Pre-injury with week 1 scores). Over the next 3 weeks, there was a steady improvement in forelimb swing in ChABC-treated animals compared with additional decline in saline-treated animals. At 4 weeks, there was a significant improvement in range of motion of the affected forelimb of ChABC-treated animals that continued through week 7 after distal graft insertion. Behavioral assessment $1 \mathrm{~d}$ after cutting of the PN graft indicated a decline in forelimb use by $\mathrm{ChABC}$-treated animals that was indistinguishable from saline-treated animals. At some point during the 7 week period for behavioral analysis, three of seven ChABC-treated rats achieved a score of 4 , whereas the maximum for the five saline-treated rats did not rise above a score of 2 .

Because behavioral recovery was not entirely eliminated in all animals by bridge relesion, mechanisms in addition to axon regeneration through the bridge must account for the maintained functionality. The absence of intact descending motor fibers below C3 ipsilateral to the injury suggests that some behavioral recovery may arise from fibers that may have sprouted from contralateral pathways. It is clear that ChABC-mediated local synaptic plasticity was not sufficient to restore useful motility, because the ChABC controls without distal graft insertion (group 4) had no restoration of useful limb movements. CSPG-rich perineuronal nets are lattice-like structures encapsulating neuronal cell bodies throughout the adult CNS that help maintain and stabilize the structural integrity of synaptic junctions (Celio et al., 1998; Murakami and Ohtsuka, 2003; Massey et al., 2006). Motoneurons and many cord interneurons have a protective perineuronal net of CSPG (Takahashi-Iwanaga et al., 1998). ChABC digestion of CSPG within the perineuronal net of cortical area 17 allows for activity-dependent plasticity in adult visual cortex, long after expiration of the critical period (Pizzorusso et al., 2002; Berardi et al., 2004). Recent evidence suggests that ChABC administration into visual cortex combined with reverse lid suture stimulates sufficient plasticity to restore normal vision to the once deprived eye in animals made amblyopic at weaning (Pizzorusso et al., 2006). In the spinal cord, ChABC treatment likely affects this extracellular covering as well as scar-associated matrix, allowing the regenerating neurons to grow more vigorously toward and make indirect or direct connections with denervated motoneurons (Bertolotto et al., 1996; Takahashi-Iwanaga et al., 1998; Murakami and Ohtsuka, 2003). It is conceivable that formation of new, functional synapses between the regenerating axons emerging from the PN graft and the target host neuronal populations may, in turn, allow an additional measure of plasticity from local circuitry or from contralateral descending fiber systems once the perineuronal net is degraded. This could explain why some recovered function persisted after the bridge lesion. The absence of functional plasticity as a result of ChABC treatment alone suggests that there may be a synergistic effect with the PN graft on local circuit remodeling, beyond that which was observed by Bradbury et al. (2002).

Our observation that $\sim 20 \%$ of the fibers in the bridge exit into the CNS raises two important questions. Why is axonal outgrowth limited even after enzyme-induced CSPG remodeling, and how can we improve the extent of regeneration? One likely reason for regeneration failure at PNS/CNS interfaces is an addictive-like behavior that develops between axons and PNS glia (Grimpe et al., 2005), in which the strong interaction of the two somehow reduces the capacity for axonal exploration beyond the graft. Another possibility may be the long-term, de novo accumulation of heavily glycosylated proteoglycans at the graft-host interface after termination of the enzyme treatment. In the face of increasing CSPGs, perhaps only the most vigorously growing fibers would have access to the cord. Strategies that might enhance the exodus of axons would include the modification of the integrin repertoire of the regenerating growth cones (Condic, 2001), the delivery of classic (Kobayashi et al., 1997) or novel (Yin et al., 2006) neurotrophins to the region of supraspinal cell bodies or to the lesion site (Ye and Houle, 1997; Ramer et al., 2000; Romero et al., 2001), or the use of a combinatorial approach to target other inhibitory molecules that are not affected by ChABC (Filbin, 2003). Techniques that allow for the sustained release of ChABC even after distal graft insertion also may be advantageous. Enhancement of the rate and efficacy of axonal elongation in the bridge (Dusart et al., 2005; Hu et al., 2005) as well as increasing the magnitude of axonal exit into and synaptogenesis within the CNS is going to be especially important in larger animals in which distances across the lesion and into the relevant spinal gray matter regions are much greater than in the rat. It also will be important to ascertain whether a conditioning effect can be identified and used to advantage in larger animals and human injury situations.

It is noteworthy to discuss the obvious advantages as well as the disadvantages of PN grafts compared with other potentially useful transplantation techniques. Schwann cells have evolved to provide severed axons with an outstanding support system for rapid regeneration via growth-supporting adhesion and trophic molecules (Mirsky and Jessen, 1999; Sherman and Brophy, 2005). As the axons journey through the bridge toward the CNS, bands of Bungner support growth along the longitudinal axis of the bridge and curtail excess sprouting in ectopic directions. Another critical biological feature of the Schwann cell is its capacity to provide new myelin for the fibers they encapsulate. Indeed, all of the structural elements necessary for maintenance of a regenerated axonal tract are assembled in a peripheral nerve with connective tissue and vascular elements in the epineuria and perineuria conferring proper tensile and elastic characteristics and a well nourished environment to the tract formed within them. Given that there is an abundant supply of PNS segments, especially in larger animals, that can be used for autografting without major declinations in function (unlike the rat), there is no need for immunosuppressive therapy or an embryonic donor. A clinical disadvantage of long-distance $\mathrm{PN}$ grafting might be the need to route the bridge outside of the cord dura mater, making it vulnerable to long-term mechanical trauma. Perhaps in larger animals, a course under the dura may be feasible. Finally, the PNS bridging strategy, although capable of stimulating relatively longdistance regeneration of efferent axon systems caudally, has yet to be demonstrated to be capable of guiding sensory axons rostrally. Nonetheless, our results demonstrate that, once allowed back 
into the spinal cord, even a relatively small number of regenerated supraspinal axons targeted to a specific spinal cord segment can promote a significant measure of functional improvement after cervical spinal cord injury.

\section{References}

Aguayo AJ, David S, Bray GM (1981) Influences of the glial environment on the elongation of axons after injury. J Exp Biol 95:231-240.

Berardi N, Pizzorusso T, Maffei I (2004) Extracellular matrix and visual cortical plasticity: freeing the synapse. Neuron 44:905-908.

Bertolotto A, Manzardo E, Guglielmone R (1996) Immunohistochemical mapping of perineuronal nets containing chondroitin sulfate proteoglycan in the rat central nervous system. Cell Tissue Res 283:283-295.

Bradbury EJ, Moon LD, Popat RJ, King VR, Bennett GS, Patel PN, Fawcett JW, McMahon SB (2002) Chondroitinase ABC promotes functional recovery after spinal cord injury. Nature 416:636-640.

Bregman BS (1994) Recovery of function after spinal cord injury: transplantation strategies. In: Functional neural transplantation (Dunnett SB, Bjorklund A, eds), pp 489-529. New York: Raven.

Bunge MB (2001) Bridging areas of injury in the spinal cord. The Neuroscientist 7:325-339.

Caggiano AO, Zimber MP, Ganguly A, Blight AR, Gruskin EA (2005) Chondroitinase $\mathrm{ABCI}$ improves locomotion and bladder function following contusion injury of the rat spinal cord. J Neurotrauma 22:226-239.

Celio MR, Spreafico R, De Basi S, Vitellaro-Zuccarello L (1998) Perineuronal nets: past and present. Trends Neurosci 21:510-515.

Chau CH, Shum DK, LiH, Pei J, Liu YY, Wirthlin L, Chan YS, Xu XM (2004) Chondroitinase $\mathrm{ABC}$ enhances axonal regrowth through Schwann cellseeded guidance channels after spinal cord injury. FASEB J 18:194-196.

Condic ML (2001) Adult neuronal regeneration induced by transgenic integrin expression J Neurosci 21:4782-4788.

David S, Aguayo AJ (1981) Axonal elongation into peripheral nervous system "bridges" after central nervous system injury in adult rats. Science 214:931-933.

Dow KE, Wang W (1998) Cell biology of astrocyte proteoglycans. Cell Mol Life Sci 54:567-581.

Dusart I, Ghoumari R, Wherle MO, Morel L, Bouslama-Oueghlani E, Camand E, Sotelo C (2005) Cell death and axon regeneration of Purkinje cells after axotomy: Challenges of classical hypotheses of axon regeneration. Brain Res Rev 49:300-316.

Filbin MT (2003) Myelin-associated inhibitors of axonal regeneration in the adult mammalian CNS. Nat Rev Neurosci 5:703-713.

Friedman B, Aguayo AJ (1985) Injured neurons in the olfactory bulb of the adult rat grow axons along grafts of peripheral nerve. J Neurosci 5:1616-1625.

Grill RA, Blesch A, Tuszynski MH (1997) Robust growth of chronically injured spinal cord axons induced by grafts of genetically-modified NGFsecreting cells. Exp Neurol 148:444-452.

Grimpe B, Pressman Y, Lupa MD, Horn KP, Silver J (2005) The role of proteoglycans in Schwann cell/astrocyte interactions and in regeneration failure at PNS/CNS interfaces. Mol Cell Neurosci 28:18-29.

Houle JD, Jin Y (2001) Chronically injured supraspinal neurons exhibit only modest axonal dieback in response to a cervical hemisection lesion. Exp Neurol 169:208-217.

Hu Y, Leaver SG, Plant GW, Hendriks WT, Niclou SP, Verhaggen J, Harvey AR, Cui Q (2005) Lentiviral-mediated transfer of CNTF to Schwann cells within reconstructed peripheral nerve grafts enhances adult retinal ganglion cell survival and axonal regeneration. Mol Ther 11: 906-915.

Jin Y, Tessler A, Fischer I, Houle JD (2002) Transplants of fibroblasts genetically modified to express BDNF promote axonal regeneration from supraspinal neurons following chronic spinal cord injury. Exp Neurol 177:265-275.

Jones LL, Sajed D, Tuszynski MH (2003) Axonal regeneration through regions of chondroitin sulfate proteoglycan deposition after spinal cord injury: a balance of permissiveness and inhibition. J Neurosci 23:9276-9288.

Kim D, Schallert T, Liu Y, Browarak T, Nayeri N, Tessler A, Murray M (2001) Transplantation of genetically modified fibroblasts expressing BDNF in adult rats with a subtotal hemisection improves specific motor and sensory functions. Neurorehab Neural Repair 15:141-150.
Kobayashi NR, Fan D, Giehl KM, Bedard AM, Wiegand SJ, Tetzlaff W (1997) BDNF and NT-4/5 prevent atrophy of rat rubrospinal neurons after cervical axotomy, stimulate GAP-43 and T $\alpha 1$-tubulin mRNA expression and promote axonal regeneration. J Neurosci 17:9583-9595.

Li Y, Field PM, Raisman G (1998) Regeneration of adult rat corticospinal axons induced by transplanted olfactory ensheathing cells. J Neurosci 18:10514-10524.

Liu Y, Kim D, Himes BT, Chow SY, Schallert T, Murray M, Tessler A, Fischer I (1999) Transplants of fibroblasts genetically modified to express BDNF promote regeneration of adult rubrospinal axons. J Neurosci 19: $4370-4387$.

Massey JM, Hubscher CH, Wagoner MR, Decker JA, Amps J, Silver J, Onifer SM (2006) Chondroitinase ABC digestion of the perineuronal net promotes functional collateral sprouting in the cuneate nucleus after cervical spinal cord injury. J Neurosci 26:4406-4414.

McKeon RJ, Schreiber RC, Rudge JS, Silver J (1991) Reduction of neurite outgrowth in a model of glial scarring following CNS injury is correlated with the expression of inhibitory molecules on reactive astrocytes. J Neurosci 11:3398-3411.

McQuarrie IG, Grafstein B, Gershon MD (1977) Axonal regeneration in the rat sciatic nerve: effect of a conditioning lesion and of dbcAMP. Brain Res 132:443-453.

Mirsky R, Jessen KR (1999) The neurobiology of Schwann cells. Brain Pathol 9:293-311.

Mitsui T, Fischer I, Shumsky JS, Murray M (2005) Transplants of fibroblasts expressing BDNF and NT-3 promote recovery of bladder and hindlimb function following spinal contusion injury in rats. Exp Neurol 194:410-431.

Murakami T, Ohtsuka A (2003) Presynaptic barrier of proteoglycans in the mature brain and spinal cord. Arch Histol Ctyol 66:195-207.

Neumann S, Bradke F, Tessier-Lavigne M, Basbaum AI (2002) Regeneration of sensory axons within the injured spinal cord induced by intraganglionic cAMP elevation. Neuron 34:885-893.

Neumann S, Skinner K, Basbaum AI (2005) Sustaining intrinsic growth capacity of adult neurons promotes spinal cord regeneration. Proc Natl Acad Sci USA 102:16848-16852.

Pizzorusso T, Medini P, Berardi N, Chierzi S, Fawcett JW, Maffei L (2002) Reactivation of ocular dominance plasticity in the adult visual cortex. Science 298:1248-1251.

Pizzorusso T, Medini P, Landi S, Baldini S, Berardi N, Maffei L (2006) Structural and functional recovery from early monocular deprivation in adult rats. Proc Natl Acad Sci USA 103:8517-8522.

Plant GW, Bates ML, Bunge MB (2001) Inhibitory proteoglycan immunoreactivity is higher at the caudal end than the rostral Schwann cell grafttransected spinal cord interface. Mol Cell Neurosci 17:471-487.

Ramer MS, Priestley JV, McMahon SB (2000) Functional regeneration of sensory axons into the adult spinal cord. Nature 403:312-316.

Ramón-Cueto A, Plant GW, Avila J, Bunge MB (1998) Long-distance axonal regeneration in the transected adult rat spinal cord is promoted by olfactory ensheathing glia transplants. J Neurosci 18:3803-3815.

Reier PJ, Houle JD (1988) The glial scar: its bearing on axonal elongation and transplantation approaches to CNS repair. In: Advances in neurology (Waxman SG, ed), pp 87-138. New York: Raven.

Reier PJ, Stokes BT, Thompson FJ, Anderson DK (1992) Fetal cell grafts into resection and contusion/compression injuries of the rat and cat spinal cord. Exp Neurol 115:177-188

Richardson PM, Issa VM (1984) Peripheral injury enhances central regeneration of primary sensory neurons. Nature 309:791-793.

Richardson PM, McGuinness UM, Aguayo AJ (1980) Axons from CNS neurons regenerate into PNS grafts. Nature 284:264-265.

Romero MI, Rangappa N, Garry MG, Smith GM (2001) Functional regeneration of chronically injured sensory afferents into adult spinal cord after neurotrophin gene therapy. J Neurosci 21:8408-8416.

Sherman DL, Brophy PJ (2005) Mechanisms of axon ensheathment and myelin growth. Nat Rev Neurosci 6:683-690.

Shumsky JS, Tobias CA, Tumolo M, Long WD, Giszter SF, Murray M (2003) Delayed transplantation of fibroblasts genetically modified to secrete BDNF and NT-3 into a spinal cord injury site is associated with limited recovery of function. Exp Neurol 184:114-130.

Silver J, Miller J (2004) Regeneration beyond the glial scar. Nat Rev Neurosci 5:146-156.

Snow DM, Lemmon V, Carrino DA, Caplan AI, Silver J (1990) Sulfated 
proteoglycans in astroglial barriers inhibit neurite outgrowth in vitro. Exp Neurol 109:111-130.

Steinmetz MP, Horn KP, Tom VJ, Miller JH, Busch SA, Nair D, Silver DJ, Silver J (2005) Chronic enhancement of the intrinsic growth capacity of sensory neurons combined with the degradation of inhibitory proteoglycans allows functional regeneration of sensory axons through the dorsal root entry zone in the mammalian spinal cord. J Neurosci 25:8066-8076.

Takahashi-Iwanaga H, Murakami T, Abe K (1998) Three-dimensional microanatomy of perineuronal proteoglycan nets enveloping motor neurons in the rat spinal cord. J Neurocytol 27:817-827.

Tom VJ, Steinmetz MP, Miller JH, Doller CM, Silver J (2004) Studies on the development and behavior of the dystrophic growth cone, the hallmark of regeneration failure, in an in vitro model of the glial scar and after spinal cord injury. J Neurosci 24:6531-6539.

Xu XM, Guenard V, Kleitman N, Aebischer P, Bunge MB (1995) Axonal regeneration into Schwann cell-seeded guidance channels grafted into transected adult rat spinal cord. J Comp Neurol 351:145-160.

Ye JH, Houle JH (1997) Treatment of the chronically injured spinal cord with neurotrophic factors can promote axonal regeneration from supraspinal neurons. Exp Neurol 143:70-81.

Yin Y, Henzl MT, Lorber B, Nakazawa T, Thomas TT, Fan J, Langer R, Benowitz LI (2006) Oncomodulin is a macrophage-derived signal for axon regeneration in retinal ganglion cells. Nat Neurosci 9:843-852. 